\title{
THE RESTORATIVE EFFECTS OF MULTI-SENSORY OPEN SPACE DESIGN - THE EXAMPLE OF JAPANESE GARDENS
}

\author{
DOI: 10.18485/arh_pt.2020.7.ch18
}

\section{_ Eva Vanista Lazarevic}

PhD, Full Professor, University of Belgrade, Faculty of Architecture, Bul. Kralja Aleksandra 73, Belgrade, Serbia, eva.vanistalazarevic@gmail.com

\author{
- Tena Lazarevic \\ M.Arch, Faculty of Architecture, University \\ of Belgrade, e-mail: tekac@hotmail.com \\ _ Jelena Maric \\ M.Arch, Teaching Assistant, Faculty of Architecture, \\ University of Belgrade, jelena.maric1989@yahoo.com
}

\begin{abstract}
The primary health issues of modern urban lifestyle are stress-related and can lead to serious damage to both physical and mental wellbeing. In this context, the topic of restorative effects of natural environments and multi-sensory design of public open space is rather significant. This particular paper aims to expand the knowledge base regarding different relations between the characteristics of urban design, sensorial aspects of space and their therapeutic and healing effect. Focusing on users' multiple sensory dimensions, sensory parks emphasize the stimulation of various senses, enhancing human communication with others, and positive emotional responses. Multi-sensory perception in a rehabilitation garden is closely related to the users' sense of existence, emotions, and physiology and it could establish a wordless "communication", which is beneficial to realize an extended emotional and existential awareness and increase the mental restorative effect accordingly.

The methodology is based on the focused literature review regarding theoretical concepts such as Environmental psychology, Attention Restoration Theory, Place Attachment, Restorative gardens, etc. Also, this paper will present the case study analysis, including expert observation of good practice examples of Japanese gardens and open public space. Therefore, this paper will examine theories and practical examples that show the therapeutic impact that the multi-sensorial approach in design has. As a result, through the methodology mentioned above the specific set of spatial guidelines for successful urban design of sensory open space will be presented.
\end{abstract}

KEYWORDS _ multi-sensory, public space, urban design, healing space, wellbeing, Japanese gardens

\section{INTRODUCTION}

In the modern era of everyday life, one of the most critical resources is public health. According to the salutogenesis based approach and the principles of Constitution of WHO health is defined as: "a state of complete physical, mental, and social wellbeing and not merely the absence of disease or infirmity" and it is a right, and as such it underpins all other fundamental rights, which belong to 
all people" (WHO, 2010d; Antonovsky, 1979). The initiative of the World Health Organization - Regional Office of Europe began, in 1987, with the launching of Healthy Urban Planning Initiative, which integrated the concept of health and wellbeing into sustainable development. Today, main health issues regarding urban lifestyle in city areas are stress-related and can lead to serious damage to both physical and mental wellbeing. In this context, the topic of restorative effects of natural environments is widely recognized as important for individuals as well as for public health in general. Urbanisation is connected with serious problems regarding public health. In developed countries, people spend the majority of their time in densely built environments, thus weakening the opportunity for people to interact with the natural environment (Cleveland, 2014; Kaplan, 1995). With the new millennia, urban theory, as well as urban design throughout the world is returning to the issue of open spaces usage, particularly regarding public open spaces. In this context, open public space is understood not as streets, alleys, buildings, but as the green environment with elements of natural setting that act as "lungs" of the city (WHO, 2017 ). Health and wellbeing of urban residents can be enhanced through the adequate usage of these well designed open green spaces. Therefore, urban planners and landscape architects have a complex role in the design of open space in order to transform them into restorative and healing environments and provide for this growing number of urban residents.

In this paper, in particular, we are dealing with the design guidelines for therapeutic environments. Good design of open space in cities worldwide is critical and multi-sensory design is considered a new paradigm for wellbeing design, which is rather significant. The aim of this paper is to expand the knowledge base regarding different relations between the characteristics of urban design, sensorial aspects of space and their restorative and healing effects. Based on the good practice examples, regarding natural and built characteristics of restorative spaces, we will try to define the set of urban design guidelines for open public space in order to increase the quality of urban life in the city.

\section{BACKGROUND RESEARCH}

The theoretical background of this research is focused on multi-sensory design principles that can transform open space into healing environments with restorative effects. In the last few decades, more and more researchers, theoretical concepts, declarations and organizations are connecting the open space characteristics, such as greenery, fresh air, sunlight and natural settings with positive health outcomes. However, this topic is not new, in past centuries, these open spaces were seen as essential components of healing in settings ranging from medieval monastic infirmaries to the variety of gardens (Djukanovic, 2016). Aside from these natural settings, built characteristics of open space can influence people behaviour and in that sense have a positive restorative effect on people (Ulrich, 1993; Ulrich et al., 1991). One of the main objectives of the healthy city concept is to provide a physical environment that supports health, recreation and wellbeing.

\section{The "restorative healing environment"}

There is growing recognition for the role of open space, focusing on green infrastructures, such as gardens and parks in overall physical and mental health and wellbeing. The therapeutic effect of open space has been a crucial topic of many scientific types of research in the last few decades. Different theories and theoretical concepts, which are dealing with the subject of restorative environments, are based on environmental psychology and psycho-evolutionary theories. Based on these two theories, different scientific concepts are developed. Psycho physiological stress reduction theory proposes that exposure to natural stimuli triggers a parasympathetic nervous system response leading to a more positive emotional state and mental health (Franco et al., 2017; Ulrich, 1983; Ulrich et al., 1991). On the other hand, well-known Attention Restoration Theory (ART) suggests that there are several components of restorative environments that are derived from nature: 1 . being away, 2 . soft fascination, 3. extent and 4. compatibility.

Regarding restorative effects of natural environments Olmsted (1865) stated that: "it employs the 
mind without fatigue and yet exercises it; it tranquillizes and yet enlivens it; and thus, through the influence of the mind over the body, gives the effect of refreshing rest and reinvigoration to the whole system" (Olmsted, F. L. (1865). p. 22, cited in Kaplan, 1995). A range of authors from psychologists and sociologists to landscape architects and urban planners are contemplating the role of nature and open space in public health and wellbeing, on different levels. Firstly, natural characteristics can contribute to physical and mental health. Restorative environments, natural views, ambient, colours and sounds can have a soothing and calming effect and influence stress reduction, which directly affects the heart rate and blood pressure (De Vries, 2010; Ulrich, 1984). Apart from natural qualities, built characteristics of open space can engage people in physical activity, sport and recreation as well as socialization and communication (Thake et al., 2017; Tyrväinen et al., 2014). These activities are strongly connected with positive behaviours that have restorative outcomes on people. Urban green spaces particularly offer health benefits for citizens in dense urban areas. In the current modern era where we are either exposed to the social distance in open public space or staying in our homes away from the natural environment, we learn to cherish restorative open spaces with their crucial significance for normal and healthy everyday living.

World Health Organization has released important publications in 2016 and 2017 (WHO, 2016; WHO, 2017) where they list and explain in detail all of the positive effects that open green space can have. In addition, the variety of studies and researchers agree that overall benefits of natural settings on people are: improved mental health and cognitive function improved functioning of the immune system and improved physical health (Thake et al., 2017; Tenngart \& Hagerhall, 2008; Tyrväinen et al., 2014; Ulrich, 1984; Ulrich et al. 1991). When speaking about the specific restorative environments, one of the main concepts that emerged from theoretical research were different kinds of gardens, such as healing gardens, which are often connected with healthcare facilities (Cooper Marcus and Barnes, 1995) and Japanese gardens, as a representation of multi-sensory natural environments.

\section{Multi-Sensory Experience of nature and its impact}

While strolling down the forest, one can, according to Echart Tolle, experience the sacredness of nature that connects us to the stillness within. In his video "a walk through nature", he talks about the acute alertness, which happens when we slow down and just observe what nature has to offer. It is essential to educate people on how to stop and to focus on the environment. According to him, what happens is the connection to the present moment while we are listening to the subtle sounds and watching the environment around us. Throughout history, the natural environment has been believed to be very beneficial for mental restoration, mainly because it stimulates all our senses, in a harmonious way, while not seeking direct attention. In the aforementioned Attention Restoration Theory, or ART, developed by Stephen and Rachel Kaplan (1989) the mental fatigue recovery stage starts, when the thoughts, concerns and worries, demanding our direct, effortful attention start flowing away, and leave some quiet space for the mind to relax. Sensory elements of open green space have been recognized firstly as an aid in the tuberculosis treatment. Also, only visual stimulants have been proven to have great healing "power" regarding studies from the early 20th century (Ulrich 1984).

\section{Sensory gardens}

Focusing on users' multiple sensory dimensions, sensory parks and gardens emphasize the stimulation of various senses, communication with others, and positive emotional responses. Multi-sensory perception in a rehabilitation garden is closely related to the users' sense of existence, emotions, and physiology and it could establish a wordless "communication", which is beneficial to realize a widespread emotional and existential awareness and increase the mental restorative effect accordingly. The following good practice examples of traditional Japanese gardens will try to explore the restorative effect of designing a space while incorporating various senses into space planning. This type of gardens has been chosen due to their unique approach regarding sensory design, that thrives from Buddhism and Zen concepts. 


\section{METHODOLOGY}

The methodology used in this particular paper is based on the critical and focused literature review regarding different theoretical concepts and case study analysis of good practice examples. Regarding the topic of urban design of healing and restorative environments, most used contemporary methodologies for research are Evidence-Based Design and Post-Occupation Evaluation. These are both collaborative techniques that put the focus on people, on individuals, on users (Ulrich et al., 1991). This research process is divided into several steps that are chronologically listed below:

_ Theoretical background research;

_ Good practice examples - expert observation research;

_ Developing a unique set of design guidelines and recommendations to be implemented in the next future to legislation.

Theoretical background research is crucial for understanding the subject of restorative and healing environments, trying to answer the questions such as: How do people perceive the environment; What makes any environment restorative; Why do we choose natural over urban spaces; How natural settings can improve overall physical and mental health and wellbeing. The answers to these questions we found in theoretical concepts, such as: Environmental psychology, Psycho-evolutionary theory, Psycho physiological stress reduction theory, Attention Restoration Theory and different theoretical concepts, mentioned and explained earlier. In addition to the theoretical, this paper will present the case study analysis, including expert observation of good practice examples of Japanese gardens, seen as multi-sensory gardens and therapeutic environments in open public space. The focus of the research is on the specific design principles and guidelines that are represented in these gardens. Through the generalization of the data, by connecting the theoretical and practical solutions, we tried to develop a unique set of design guidelines and recommendations for the multi-sensory design of open space. In the next chapter, we are going to systematically present some of the results of this research.

\section{RESULTS - CASE STUDY}

In this paper there is the intention to show one of most significant case study as Japanese row model, already mentioned as pioneer activists in this topic, we are going to present the overview of our observation regarding restorative, sensory types of environments. We will analyze ways in which different senses are stimulated and planned, using landscaping tools.

Japanese gardens are traditional gardens deriving from Japan, designed to unfold the essence of nature. They are a perfect combination of the natural landscape and man-made scenery, constantly changing and evolving over time and different seasons. They are meticulously planned sanctuaries that integrate all the senses, creating a calming atmosphere that aims to clean the mind and awaken the soul.

Visual elements of Japanese gardens: The visual side of Japanese garden design highlights transience and imperfection following the dynamic essence of Zen philosophy. This system could be related in historian difference between French gardens, perfectly organized in symmetry and an English one, known for its natural imperfection with intent. Since there are many visual elements we will focus here only on a few, most distinguished ones, such as: (1) The balance and asymmetry; (2) The fractal composition of Ryoanji temple; (3) The Borrowed Landscapes (Shakkei): Travelling through space and time;

(1) The balance of a-symmetry: This concept is derived from the dynamic philosophy of Zen and Tao. After the Japanese civil war in the 15th century, and the rise of Zen Buddhism, the idea of experiencing the garden as a dynamic process brought the idea of asymmetrical balance. In the Book of Tea, Kakuzo Okakura writes that only the one who completes the incomplete can discover true beauty. For him, the power of life and art is in their (dynamic) ability to grow. According to ART by Kaplan and Kaplan, such an environment restores the mind by stimulating effortless attention, 
followed by a sense of mystery and continuous motivation for discovery, valuable for avoiding the feeling of boredom (Kaplan \& Kaplan, 1989). Several design elements are part of this concept: Asymmetrical composition of garden elements (rocks, shrubs, trees, water features); The elements would form compositional triangles, with uneven sides, always guiding the eyes to different parts of the garden. This would enhance the sense of the depth of space, leading the eyes to zig-zag along with the garden; The rocks, the bone structure of a Japanese garden, are always placed in groups of odd numbers - $3,5,7$, emphasizing the sense of incompleteness; In order to obtain the sense of harmony and serenity, a general rule of golden ratio was used for the spacing and rhythmic play between elements.

(2) The fractal composition of Ryoanji temple: Kyoto's Ryoanji Temple, is one of the most famous zen gardens consisting of a composition of 15 rocks spread across a gravel field. Esther Sternberg, in her book "Healing Spaces", explained that only recently the researchers from Japan, discovered using a technique called medial-axis transformation, the fractal pattern behind the rock cluster composition. According to this research, the rock clusters, when observed from a slight left point of veranda (where visitors sit), form the fractal contour of a tree, growing into branches as the vision flows down the garden (he total thickness of the branches at a particular height is equal to the thickness of the trunk). Ary Goldberger, a professor of cardiology at Harvard Medical School, suggested that when we gaze at fractal structures ("porous" holiness, carved-out appearance, the repetition of various shapes in nature or gothic churches), our mind responds to the complex, repetitive, increasing-decreasing patterns. Freed from rigid boundaries of scale, the mind can move inward or outward, up or down, at will. (Sternberg, 2009). In addition to the fractal composition, the absence of sensory stimulation is considered a very powerful meditation tool of the abstract Zen gardens. The whiteness of vast gravel fields in between the very few rocks, calls for an unfocused, meditative gaze.

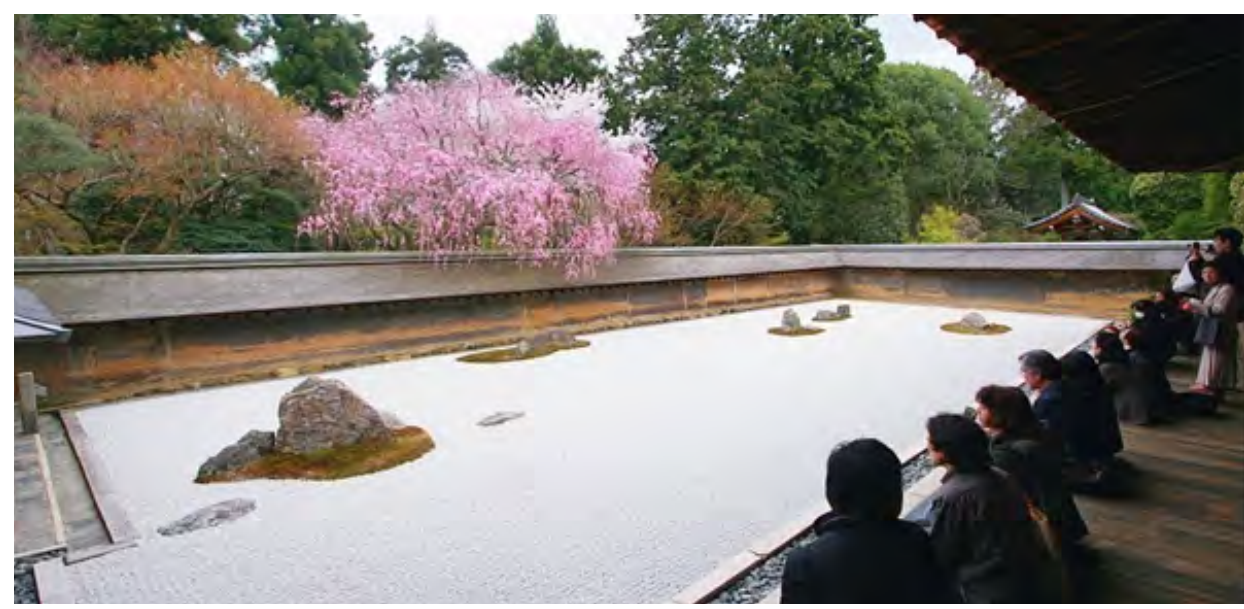

_ Figure 1: Kyoto's Ryoanji Temple: source: www.japan-guide.com

(3) The Borrowed Landscapes (Shakkei): Travelling through space and time: Shakkei or Borrowed Scenery is a design principle where the background elements such as mountains or trees are integrated into the landscape, manipulating the viewer's perspective. In this way, the boundary between interior and exterior disappears. The famous scenes similar to postcards (like Mount Fuji) were scaled and reproduced by precise positioning of stones, gravel, and other greenery, in relation to the background. Therefore, the promenade through the garden allowed an imaginary time and space travel through all these different environments. According to ART, when facing mental fatigue, a great rescue and restoration tool could be travelling to the other worlds, where we discover beautiful, serene places that foster a sense of awe. 
Sonic elements of Japanese gardens: The landscape appeals to all senses. The shape of gardens and chosen materials create specific aural environments - scenes.

The setting of Japanese tea house gardens (rojiniwa) developed in the 16th century with the tea master Sen no Rikyu and the first independent tea house. It combines the elements of gardening and serving tea. In order to reach the tea house, one needs to cross the Roji (path) through inner and outer gardens. The outer garden serves as a sonic buffer zone, with more controlled landscaping. The inner garden is a place for quietness, positioned to be away from the outside noise. There, a more natural arrangement of plants occurs, with deep tree shades, a carpet of moss and lightly trimmed to follow a natural look. One can be in the middle of the city and yet feel as if they are in the woods, Kakuzo Okakura writes in the book of tea. The idea behind the Roji path leading to the tea house is to represent a break from the everyday thoughts and worries. In the other types of gardens, like stroll gardens, different sonic interventions occur. Michael D. Fowler, in his book called Sound World of Japanese gardens, explains how visual and aural elements are intertwined. He calls this phenomenon an acoustic horizon: "Waterfalls are obvious design features that provide an aural content that can focus attention locally, or equally mask the exterior, or articulate a particular region in the garden through an auditory zone or acoustic horizon" (Sound World of Japanese gardens, page 35). He further explains that the tuning of the sound produced by water is done by different placement of rocks and variation of drop depth. In addition, in order to plan various acoustic zones, special attention is paid to positioning the greenery in the gardens: different atmospheres emerge according to places where birds are feeding, roosting or crickets singing. Berry trees or shrubs invite birds. The bird sounds are particularly important as a restoration tool, because their presence, subconsciously, represents the lack of danger in a natural environment.

Textures: Along the Roji path, the rustic, naturally looking stepping-stones are carefully chosen to slow down the movement of the visitors. As visitors walk into the peaceful, natural environment of the inner tea garden, they should get the feeling of travelling long distances: out of the hectic everyday life in the city into the serene, far away forests and mountains. Thus, while walking slowly across the stepping stone path, there is enough time to calm down and release the mind chatter, before arriving restored to the tea house. Sometimes the water is poured over the stepping stones, making it slippery, so one would walk even more slowly and carefully, watching every step.

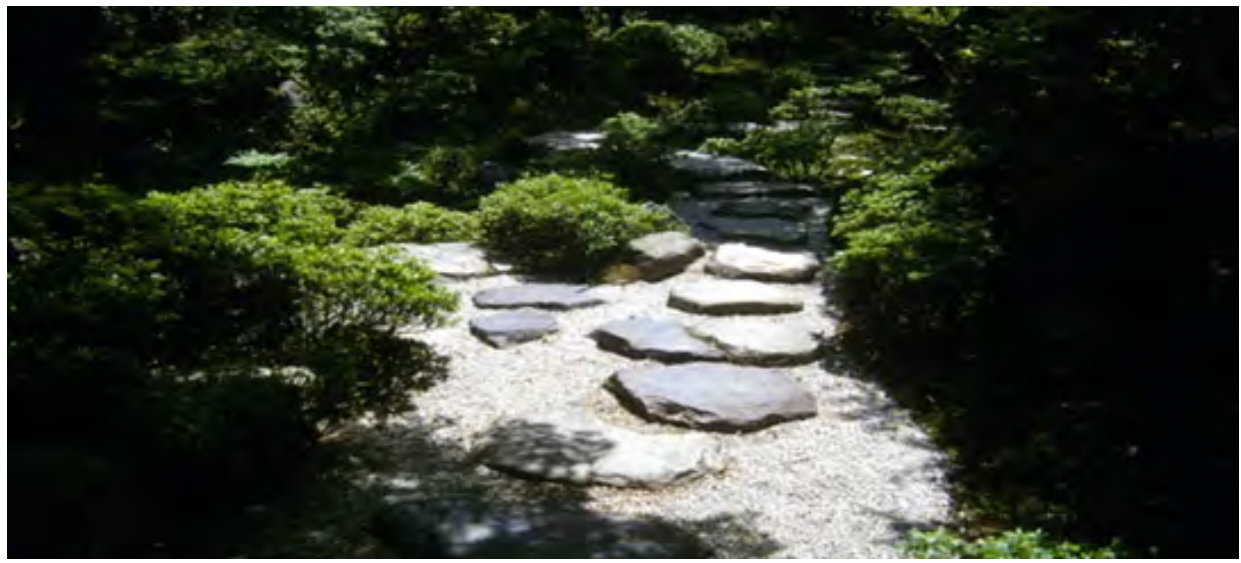

_ Figure 2: Roji path, source: https://learn.bowdoin.edu/

Often, as well as other sensory cues, textures are chosen to manipulate viewers' perception of reality. Rocks symbolically represent different natural elements: rivers, sea, mountains, lakes, evoking the feeling of distant landscapes. When representing mountains, for example, rocks have pyramid shapes, with jagged or stepped edges. When they represent rivers and shorelines, their shapes are smooth rounded or flat. Since their role is just to sparkle imagination and open a mental space to 
different worlds, they are planned only to be viewed from a distance and meditated upon. Plants can also affect the sense of scale in the site. For example, fine detailed textures of moss or juniper on the rocks enhance their size, shrubs and groundcovers evoke fields or forest floors, creating a very relaxing sensory ambience. Wildflowers like irises, or ferns, bring a sense of grace to the overall atmosphere.

Smell: Fragrance is not always necessary in Japanese gardens. The natural feel calls for subtleness, freshness (of forest pines and moss) and delicacy, unlike modern sensory gardens which are very intense. But sometimes, fragrant plants are still planted, such as: Winter Daphne, Common gardenia or Rhaphiolepis umbellate.

Within this chapter, we have identified some of the most distinguished features of Japanese gardens in the context of unique sensory design. In the following table, we summarised some of the aforementioned design principles as recommendations and guidelines for gardens in order to transform them from mere green space to restorative or healing environments.

Within this chapter, we have identified some of the most distinguished features of Japanese gardens in the context of unique sensory design. In the following table, we summarised some of the aforementioned design principles as recommendations and guidelines for gardens in order to transform them from mere green space to restorative or healing environments.

Once when the importance of healing places are implemented as a most needed element in the new organization of public spaces in the years to come, it would be wise to insert those guidelines in booklets or manuals for their design or even as the parts of legal obligations and official guidelines. Only when inserted in legislation, new investors and/or city councils will have to use them and fully implement in. These regulations are already, fully or partially implemented in countries such as Holland of France.

_ Table 1: General design recommendations for sensory gardens and healing spaces, source: author

\begin{tabular}{|l|}
\hline A) General recommendations \\
\hline Assemble a team of experts before the beginning of the design project \\
\hline Enable the participation of users / evidence-based design \\
\hline Use natural potentials of the location/greenery, sunlight, fresh air, etc. \\
\hline Respect the context and identity of the place \\
\hline Enable a sense of control and peace and comfort \\
\hline Engage all the senses \\
\hline
\end{tabular}

_ Table 2: Design guidelines for sensory gardens and healing spaces, source: author

\begin{tabular}{|l}
\hline B) Design suggestions: \\
\hline $\begin{array}{l}\text { Use natural, rustic materials; } \\
\text { Pay special attention to positioning the greenery in the gardens }\end{array}$ \\
\hline Use the balance of a-symmetry /asymmetrical composition of garden elements \\
Design curving and bending paths, using various natural textures that would speed or slow the movement, \\
for intimacy and mystery ("the beauty lies in the tension of the unknown")
\end{tabular}

for intimacy and mystery ("the beauty lies in the tension of the unknown") 
Design curving and bending paths, using various natural textures that would speed or slow the movement, for intimacy and mystery ("the beauty lies in the tension of the unknown")

Use the principles of the golden ratio

"Imitating the principles of nature" with the fractal composition of key landscape elements in the garden

"Borrowing the distant scenery or the context beyond the garden", gradual positioning of elements from smallest to biggest in the background; emphasize the sense of depth with colour: blue, dark green and grey for the background, yellow and white for the foreground

Design quiet places deprived too much sensory stimulation, such as Dry Zen gardens, for meditation, sensory breaks.

Combine the elements of gardening and serving tea, such as designing a viewing shelter or a tiny house in the garden where people can pause and rest, drink a tea.

Design several sound devices:

-Discrete dripping or murmuring water for tranquillity

-Waterfall insulates exterior noise and generates good sound - the water barrier

-A water pond or a hard surface such as stone reflects environmental sounds

-Plan the bird sounds, by planting shrubs that attract them and water basins

Design space with subtle smell, freshness and delicacy.

Plan the smells, sounds and foliage colours throughout different seasons

\section{CONCLUSIONS}

In the era of increased stress and health-threatening issues that surround us, the main focus regarding our habitat and living environment should be on preserving natural resources and increasing overall public health and wellbeing. A paradigmatic shift towards an integrative understanding of the determinants of health and wellbeing extended the health preservation beyond the healthcare institutions and emphasized the role of the environment.

We, as people, are drawn to natural environments and open space. This paper summarised the existing evidence of significant positive effects of urban open spaces and natural green surroundings on people. Therapeutic environments offer many public health benefits, such as psychological relaxation and stress reduction, enhanced physical activity, immune system elevation and overall physical health.

Urban planners and landscape architects have a complex role in the design of urban open space in order to transform them into healing environments and provide for this growing number of urban residents.

There is a strong connection between multi-sensory environments and restorative or healing spaces. Traditional Japanese gardens are a great example of a multi-sensorial space, portraying the Universal laws on a subconscious, bodily level, through various visual and aural scenes, as well as smell and touch. Therefore, every single bush or flower is planted carefully, every stone positioned with a precise function. While slowly moving through the garden, one gently gets to explore different times and places. The most intense restorative effect comes from shifting the focus from the self-absorbed mind to the bodily sensations, leaving Isabelle Stengers much space for rejuvenation and restoration of mind and body. Planning this kind of complete and complex experience can be a great inspiration for today's architects and planners, who often neglect the importance of various senses in the design process of restorative places. 
These sensory values of gardens and natural settings are recognized on the national level, promoting green urban re-use of old industrial and infrastructure heritage, such as "Highline" project in New York, or similar ones in Paris and other parts of Europe. Even the "common men", intuitively, understand the impact of nature, with the example of urban community gardens that are developed inside the living area by the inhabitants themselves.

Overall, the main contributions of this particular paper are expanding the knowledge base regarding restorative effects of open public space on our health and wellbeing and defining a set of universal recommendations and guidelines for multi-sensory open space with restorative effects.

\section{REFERENCES}

Books:

- Antonovsky, A., 1979. Health, stress, and coping. San Francisco: Jossey-Bass.Cooper

- Đukanović, Z. (Ed.). (2016). Otvoreni prostori zdravstva: Open health spaces. Beograd: Univerzitet u Beogradu, Arhitektonski fakultet.

_ Gehl, J. (2011). Life between Buildings: Using Public Space. Washington: Island Press.

- Marcus, C., \& Sachs, N. A., 2014. Therapeutic landscapes. An evidence-based approach to designing healing gardens and restorative outdoor spaces. Hoboken, New Jersey: John Wiley \& Sons.

_ Fowler D. Michael. 2014. Sound Worlds of Japanese Gardens, An Interdisciplinary Approach to Spatial Thinking. Berlin: Transcript-Verlag

- Hara, Kenya. 2019. 100 Whites. Zürich: Lars Müller Publishers

_ Kakuzō, Okakura. 1906. The Book of Tea. New York: Duffield \& Company

- Kaplan, S., \& Kaplan, R., 1989. The experience of nature: A psychological perspective. New York: NY: Cambridge University Press.

- Musgrave, Toby, Lincoln, Frances. 2015. Paradise Gardens: Spiritual Inspiration and Earthly Expression, London: Lincoln Publishers Ltd, 2015

- Olmsted, F. L., 1865. The value and care of parks. Reprinted in Nash, R. (Ed.) (1968), The American Environment: Readings in the history of conservation. Reading, MA: Addison-Wesley, pp. 18-24.

- Pallasmaa, Juhani. 2012. The eyes of the skin. Hoboken: John Wiley \& Sons Inc

- Sternberg, M. Esther. 2009. Healing Spaces, The Science of Place and Well-Being. London: Belknap

Press of Harvard University Press

- Ulrich, R., 1984. View through a window may influence recovery from surgery. Science 224(4647), 420. https://doi.org/10.1126/science.6143402

- Book chapter:

_ De Vries, S. (2010). Nearby nature and human health: Looking at the mechanisms and their implications. In: W.Thompson, P. Aspinall and S. Bell. (Eds.) Innovative Approaches to Researching Landscape and Health. Abingdon: Routledge.

- Journal article:

- Cleveland, A. C. 2014. Symbiosis Between Biophilic Design and Restorative Healing Environments: The Impact on Overall Well-Being of Urban Dwellers. Retrieved from http://purl.flvc.org/fsu/fd/FSU_migr_etd8958).

- Cooper Marcus, C. and Barnes, M. (1995). Gardens in healthcare facilities: Uses, therapeutic benefits, and design recommendations. Retrieved from https://www.healthdesign.org

_ Franco L.S., Shanahan D.F., Fuller R.A. 2017. A review of the benefits of nature experiences: More than meets the eye. Int. J. Environ. Res. Public Health. 2017;14:864. doi: 10.3390/ijerph14080864.

- Kaplan, S., 1995. The restorative benefits of nature: Towards an integrative framework? Journal of Environmental Psychology, 15(3), 169-182.

- Thake, C., Bambling, M., Edirippulige, S. and Marx, E. (2017). A psychoevolutionary approach to identifying preferred nature scenes with potential to provide restoration from stress. HERD: Health Environments Research \& Design Journal, 10(5) https://doi.org/10.1177/1937586717705085. 
- Tenngart Ivarsson, C., \& Hagerhall, C. M. 2008. The perceived restorativeness of gardens -assessing the restorativeness of a mixed built and natural scene type. Urban Forestry and Urban Greening, 7 , 107-118.

- Tyrväinen, L., Ojala, A., Korpela, K., Lanki, T., Tsunetsugu, Y., \& Kagawa, T. 2014. The influence of urban green environments on stress relief measures: A feldexperiment. Journal of Environmental Psychology, $38,1-9$.

- Ulrich, R. S., Simons, R. F., Losito, B. D., Fiorito, E., Miles, M. and Zelson, M. (1991). Stress recovery during exposure to natural and urban environment. Journal of Environmental Psychology, 11, 201-230.

_ WHO. 2010d. Urban Planning, Environment and Health: From Evidence to Policy Action. Meeting Report. Copenhagen, Denmark: WHO Regional Office for Europe.

_ WHO 2019. Constitution of the World Health Organization: Basic Document. WHO; Geneva, Switzerland [(accessed on 10 September 2019)]. Available online:https://www.who.int/governance/eb/who_constitution_en.pdf.

_ WHO 2016. Urban green spaces and health. Copenhagen: WHO Regional Office for Europe.

_ WHO 2017. Urban green space interventions and health. Copenhagen: WHO Regional Office for Europe. - Internet source; Japanese gardens; design and concept, Accessed on February 2020; http://www. japanese-gardens.info/plants/distinctive-shrubs.html; https://books.google.rs/books?id=-El BgAAQBAJ\&pg=PA $188 \& \mathrm{lpg}=P A 188 \& \mathrm{dq}=$ sunset+as+important+restorative+tools\&source=bl\&ots=bILVNXvrRr\&sig=ACfU3U19bNxORnKIXOYc_Xuv_rp8gGeZRA\&hl=en\&sa=X\&ved=2ahUKEwi1hZC57_HoAhVFs4sKHSDPD9YQ6AEwAHoECAwQKA\#v=onepage\&q=sunset\%20as\%20important\%20restorative\%20 tools\&f=false; https://www.japan-guide.com/e/e2099_elements.html; http://www.japanese-gardens. info/plants/distinctive-shrubs.html; https://japanesegarden.org/garden-spaces/tea-garden/;https:// www.japan-guide.com/e/e2099_elements.html; https://www.youtube.com/watch?v=iVaoDNEZwNg; https://www.youtube.com/watch?v=RPcYrUQN44g\&t=594s https://soundzipper.com/blog/sound-environment-japanese-gardens/know a certain space has affected the architecture in terms of interlocking the cyberspace with the material space (Virilio, 2011). The contemporary city concepts require the use of new technology when interpreting elements of cultural heritage in public spaces. The new relation between technology and space is being constructed, and it serves as a medium of digitalized interaction in the form of digital projections, 3D Mapping, holograms, augmented reality installations, and different means of virtual or mixed reality activities. With such use, the technology becomes both the activator and the generator of the public life and also gives new meaning to the relation of time-space-information (Renaud, 2002). 